\title{
Case Report on Sleeve Avulsion of Patella in Young Adult
}

\author{
Faheem Quraishi ${ }^{1}$, Iram Khan ${ }^{1}$, A. G. Quraishi ${ }^{1}$ \\ Learning Point of the Article: \\ To diagnose rare sleeve avulsion of patella in adults and treat it effectively with Krackow pullout Suture technique.
}

\section{Abstract}

Introduction: Sleeve avulsion of patella is extremely rare, limited almost to children. However, few cases have been reported in adults. Rarity of this fracture makes the diagnosis and choice of treatment difficult. Inability to raise leg remains important clinical sign for quadriceps mechanism insufficiency. In the absence of standard treatment guidelines pullout sutures through patella provides a secure and stable fixation option. Our case remains the first to be reported ever in English literature in a 23 -year-old male with a superior pole avulsion patella being treated with Krakow pullout suture.

Case Report: A 23-year-old Indian male was admitted with left knee pain and swelling following fall from bike. He had knee pain, swelling, and inability to bear weight. Active straight leg raising was not possible. On X-ray he had small bony sleeve visible near proximal pole of patella. Magnetic resonance imaging (MRI) was done which showed sleeve avulsion of patella at proximal pole. Under spinal anesthesia fracture was exposed through midline approach. Pullout Krakow sutures were taken through quadriceps tendon and fracture fragments using 3 no Polyester suture. Transosseous tunnels were drilled in patella and tied distally. At 4 months patient had no extension lag with full range of movements. At 14 months follow-up patient is asymptomatic and able to run, squat, sit cross legged, and do his day-to-day activities.

Conclusion: Sleeve avulsion of patella in adults is extremely rare with only few cases reported in literature. MRI is not only useful for diagnosis but also for deciding treatment modality. Krackow technique with Polyester suture through quadriceps tendon incorporating fracture fragment passed through patellar transosseous tunnel provides secure fixation with excellent results. Also avoids any future hardware problems in this subcutaneous bone.

Keywords: Sleeve avulsion, Krakow suture, pull out technique.

\section{Introduction}

Sleeve avulsion of patella is rare in children and seen under 16 years [1]. It can be attributed to immature osteochondral junction in adolescents as compared to fully ossified adult patella. Avulsions are rare in upper pole than lower pole, few being reported in early adolescents. Sleeve avulsions of patella are extremely rare in adults [2]. Diagnosis can easily be missed due to the small fragment. Proper evaluation demands an magnetic resonance imaging (MRI) scan for both diagnosis and treatment. As per the available English literature only four cases have been reported in other age groups till date. Out of which three were males and one female $[3,4,5]$. We present sleeve avulsion of patella for the 1st time in 23 years age group. Moreover, we describe the use of Krakow pull out suture never described before for sleeve avulsion of proximal pole of patella. The functional results have been excellent at 14 months followup.

\section{Case Presentation}

A23-year-old Indian male presented with the left knee pain with swelling and inability to bear weight after a fall from bike. There

\begin{tabular}{|c|c|c|c|}
\hline & & 's Photo Gc & \\
\hline \multicolumn{4}{|l|}{ Access this article online } \\
\hline \multicolumn{4}{|l|}{$\begin{array}{c}\text { Website: } \\
\text { www.jocr.co.in }\end{array}$} \\
\hline $\begin{array}{c}\text { DOI: } \\
\text { 10.13107/jocr.2021.v11.i03.2104 }\end{array}$ & \multicolumn{3}{|c|}{$\begin{array}{l}\text { 'Department of Orthopaedics, Orthocare Accident Hospital and Research Centre, Nandgaon Road, Manmad, District -Nashik, Maharashtra State, India. } \\
\text { Address of Correspondence: } \\
\text { Dr. Faheem Quraishi, } \\
\text { Department of Orthopaedics, Orthocare Accident Hospital and Research Centre, Nandgaon Road, Manmad, District -Nashik, 423 104, Maharashtra State, India. } \\
\text { E-mail: quraishifaheem@gmail.com }\end{array}$} \\
\hline
\end{tabular}

Journal of Orthopaedic Case Reports | pISSN 2250-0685 | eISSN 2321-3817 | Available on www.jocr.co.in | doi:10.13107/jocr.2021.v11.i03.2104 This is an Open Access article distributed under the terms of the Creative Commons Attribution Non-Commercial License (http://creativecommons.org/licenses/by-nc/3.0) which permits unrestricted non-commercial use, distribution, and reproduction in any medium, provided the original work is properly cited. 


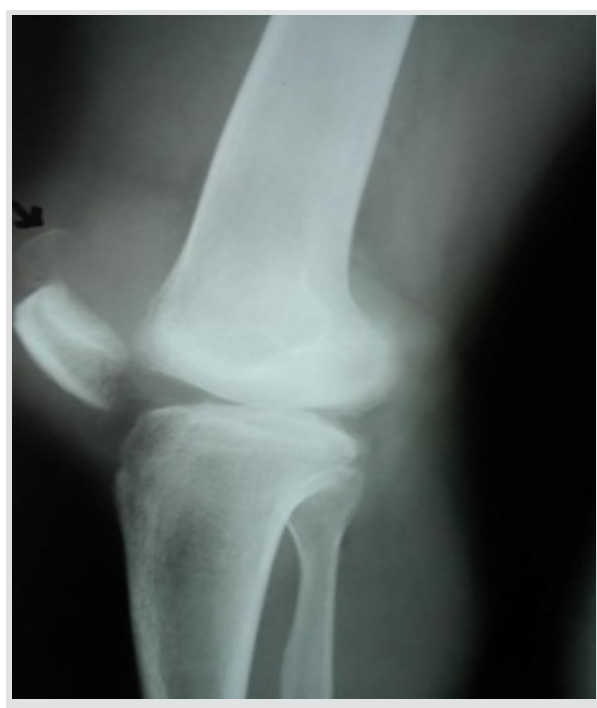

Figure 1: X-ray showing sleeve of bone avulsed at proximal pole o patella.

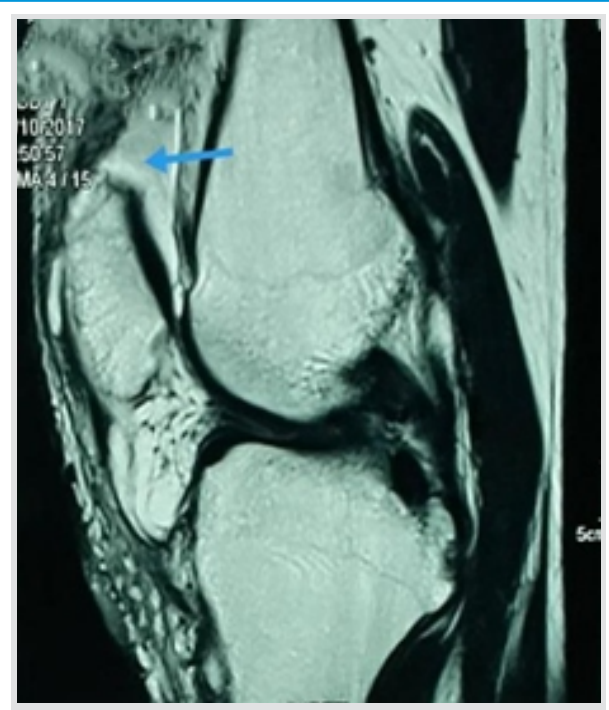

Figure 2: MRI scan showing bony sleeve avulsion of patella.

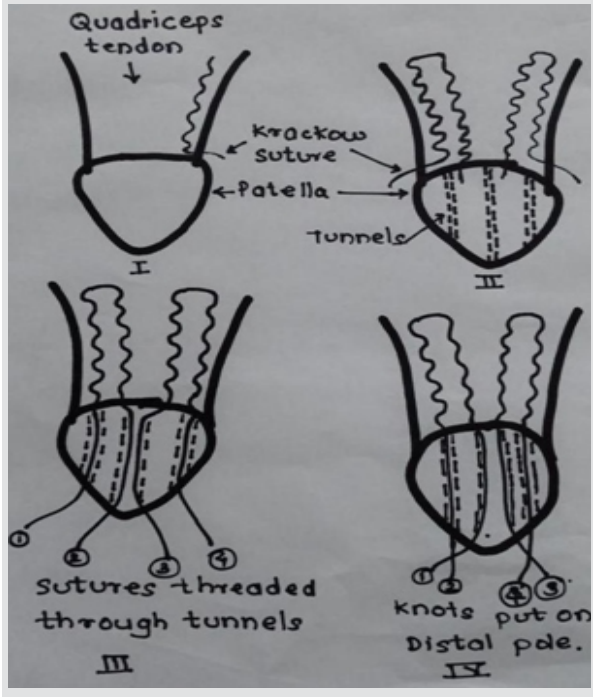

Figure 3: Schematic representation of surgical technique.

was swelling over knee and movements were restricted due to pain. Straight leg raising was not possible. X-ray was taken in the casualty, which showed flake of bone over proximal pole of patella (Fig. 1). A knee immobilizer brace was applied. On 3rd day though, the swelling subsided straight leg raising was not possible. An MRI was done which showed sleeve avulsion of patella at proximal pole, more posteriorly than anteriorly (Fig. 2 ). The avulsed fragment was comminuted and was not big enough to allow screw fixation. Surgery was planned as due to discontinuity in quadriceps mechanism patient was unable to extend the knee actively and perform straight leg raising.

\section{Surgical technique}

Krakow suturing through quadriceps tendon incorporating fracture fragments pulled out of patellar tunnel were planned (Fig. 3). Under spinal anesthesia and tourniquet a midline approach were used to expose anterior aspect of patella and distal quadriceps tendon. The avulsed fragments were reached from anterior aspect (Fig. 4a).

The fracture edges were freshened (Fig. 4b). In four vertical

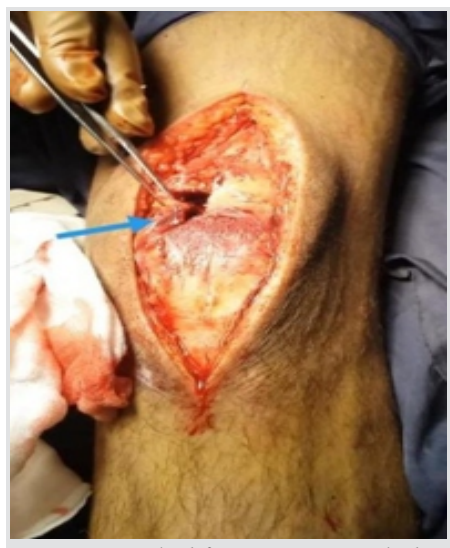

Figure 4a: Avulsed fragment seen attached to quadricepstendon.

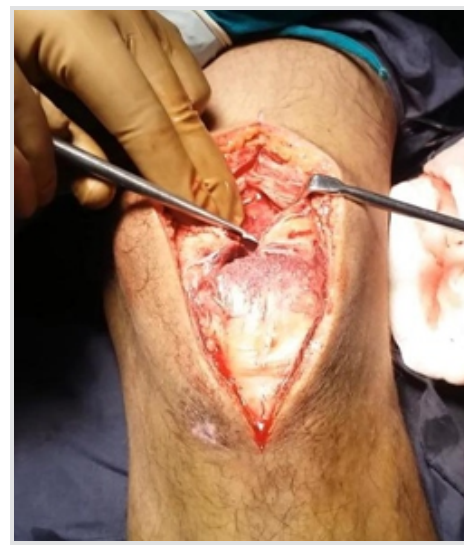

Figure 4b: Fracture edges freshened with curetted.

rows with no.3 Krakows sutures were taken incorporating fracture fragments [Figure 4c]. From four polyester suture rows now 4 thread ends were available [3]. Tunnels were drilled in patella in proximal to distal direction (Fig. 4d). The medial threads are pulled out of middle tunnel and the lateral threads are pulled out of corresponding lateral tunnels [Figure 5a]. On the distal end of the tunnels the medial thread ends are passed through the soft tissue to the corresponding lateral threads to avoid placing knots on anterior aspect. Tight knots were taken to ensure good opposition at fracture site (Fig. 5b). Additional sutures were taken in quadriceps tendon where gap was seen. Secure fixation was confirmed by passive flexion of knee to 90 . Wound was closed in layers with Vicryl and ethilon suture. Knee was immobilized in knee immobilizer splint.

\section{Post-operative mobilization}

Knee was immobilized in extension for 3 weeks non weight bearing. Then, gradual passive ranges of movements were started and partial weight bearing was allowed for 3 weeks, followed by full weight bearing. However, the patient developed

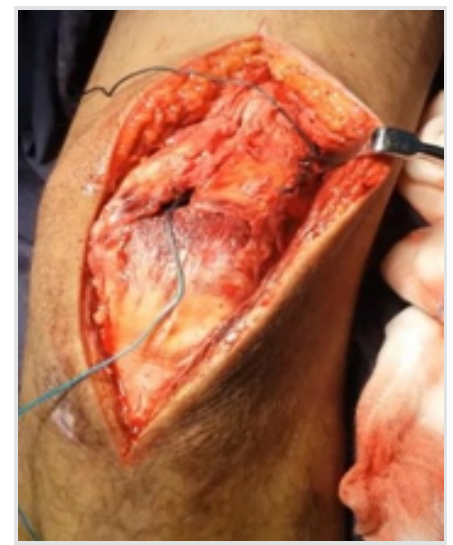

Figure 4c: Vertical Krakow suture through quadriceps tendon.

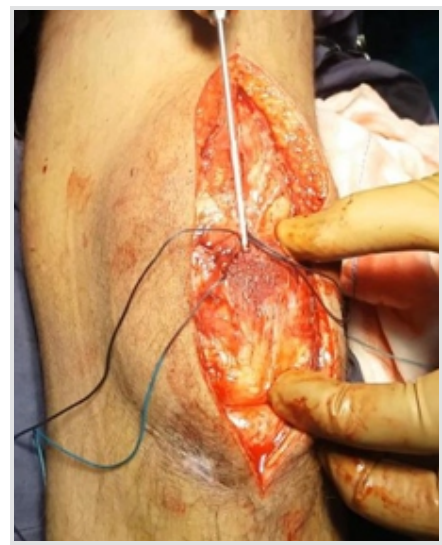

Figure 4d: 3 osseous tunnel drilled through patella. 


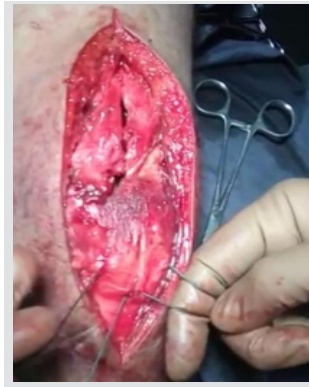

Figure 5a: 4 Threads available at distal patella to tie knot.

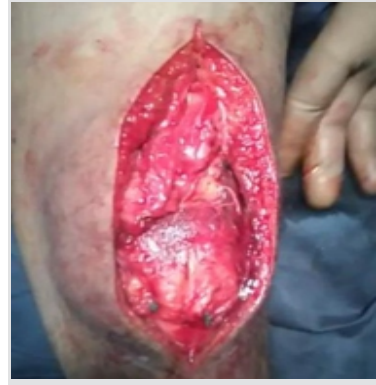

Figure 5b: Knots are tied on corresponding sides.

\begin{tabular}{|c|c|c|c|c|c|c|c|}
\hline \multicolumn{7}{|c|}{ Table 1: All reported cases of sleeve avulsion of patella in adults } \\
\hline Case & Year & Sex & Age & History & Location & Treatment & $\begin{array}{c}\text { Follow-up } \\
\text { Current }\end{array}$ \\
2017 & Male & 23 & Healthy & Upper pole & Surgery & $\begin{array}{c}\text { Full recovery } \\
\text { after 4 months }\end{array}$ \\
1 & 2014 & Female & 19 & Healthy & Upper pole & Surgery & $\begin{array}{c}\text { Full recovery } \\
\text { after 26 months }\end{array}$ \\
\hline 2 & 2014 & Male & 24 & Healthy & Upper pole & Surgery & $\begin{array}{c}\text { Full recovery } \\
\text { after 26 months }\end{array}$ \\
\hline 3 & 2013 & Male & 22 & Healthy & Upper pole & Conservative & $\begin{array}{c}\text { Function regain } \\
\text { after 3 weeks }\end{array}$ \\
\hline 4 & 2003 & Male & 30 & $\begin{array}{c}\text { Osteogenesis } \\
\text { Imperfecta }\end{array}$ & Upper pole & Surgery & $\begin{array}{c}\text { Fracture union } \\
\text { after 6 months }\end{array}$ \\
\hline
\end{tabular}

osteogenesis imperfecta. Except for such pathological skeleton, only three cases of sleeve fractures in healthy adults have been reported in the English literatures till date [3, 4]. However, the presented case remains unique to be presented for the 1st time in 23-year-old male, the treatment done with Krakows suture adds to its importance as to be described as a treatment option for the first time in superior pole avulsion in adult patella.

Diagnosis can often be missed on X-ray as the fragment is usually just a sleeve of bone. Clinical unfamiliarity, rarity, and tiny size of fragment demands high degree of suspicion for diagnosis. MRI remains the ideal imaging. It not only quantifies the bony size but also helps delineate the quadriceps injury, amount of proximal retraction and quadriceps mechanism disruption [7].

Treatment options include non-operative and operative management depending on the fragment displacement and size. In our case, discontinuity of quadriceps mechanism leading to loss of active extension and displaced fragment was the indication of operative fixation. Failing to choose optimal treatment may result in quadriceps lag, atrophy, stiffness, and weakness [1], [2], [8]. Altered patella tracking can call in early patellofemoral arthritis. Conservative management includes immobilization in plaster cast. Conservative management usually leads to unsatisfactory results [6], [9]. If fragment displacement is $<2 \mathrm{~mm}$, cast immobilization in knee extension can be a choice. However, prolonged immobilization can lead to knee stiffness. In our case, though we immobilized knee postoperatively for just 3 weeks, followed by passive mobilization, we encountered stiffness warranting adhesiolysis.

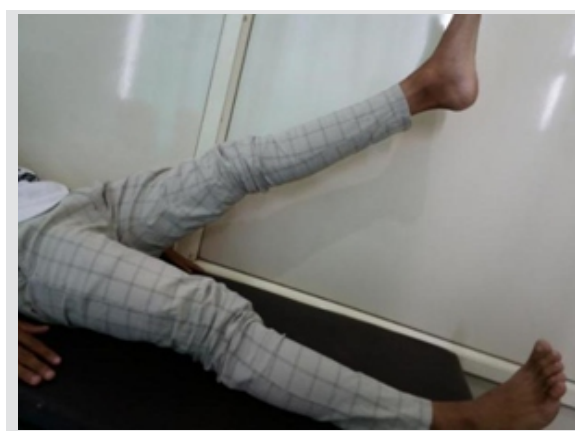

Figure 6a: No extensor lag seen.

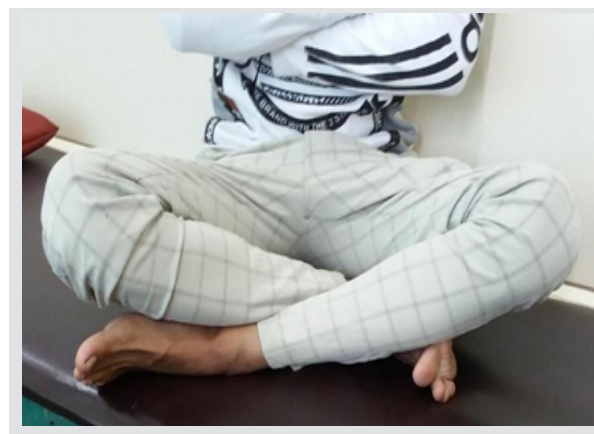

Figure 6b: Full functional range achieved without any residua stiffness.

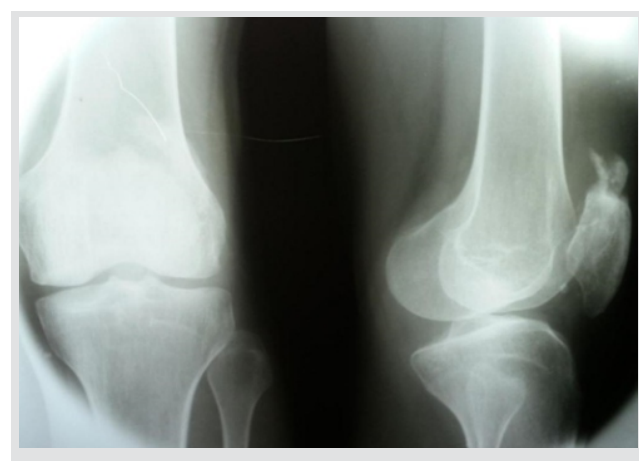

Figure 6c: Follow-up X-ray

Journal of Orthopaedic Case Reports | Volume 11 | Issue 3 | March 2021 | Page 94-97 
For early knee mobilization postoperatively, a secure fixation is a must. Use of Krakow suture through quadriceps tendon incorporating fracture fragments not only brings patella fragments together but also negates the distracting force of quadriceps muscle and of knee flexion. This allows for early postoperative knee flexion and easy rehabilitation. Transosseous sutures are useful but suture anchor can also be used [10], [11]. While choosing fixation technique another point to be considered is hardware problem, as patella is a subcutaneous bone. Pullout Krakow sutures tied on the anterolateral aspect on both sides overcomes this problem. Moreover, there is no hardware removal issue averting another surgery in future.

\section{Conclusion}

Sleeve avulsion of patella in adults is extremely rare with only few cases reported in literature. MRI is not only useful for diagnosis but also for deciding treatment modality. Krakow technique with polyester suture through quadriceps tendon incorporating fracture fragment passed through patellar transosseous tunnel provides secure fixation with excellent results in this rare injury. This also prevents any future hardware problems in this subcutaneous bone.

Clinical Message

Treating rare fractures like sleeve avulsion of patella can be challenging. However, thorough understanding of the fracture mechanism, diagnosis, and treatment methods makes its management easier. Legendary Krakow suture proves ideal fixation method in this particularly rare injury. However, in future with more cases, new treatment modalities will emerge and also may testify our modality.

\section{References}

1. Hunt DM, Somashekar NA. Review of sleeve fractures of the patella in children. Knee 2005;12:3-7.

2. Ray JM, Hendrix J. Incidence, mechanism of injury, and treatment of fractures of the patella in children. J Trauma 1992;32:464-7.

3. Ro KH, ParkJH, Kim MJ, Lee DH. Rare sleeve fracture of the superior patella pole in an adult due to forceful passive physiotherapy following cast immobilization. Knee 2014;21:600-4.

4. Teixeira PA, Lecocq S, Moisei A, Chanson A, Louis M, Blum A. Sleeve-like avulsion fracture of the superior pole of the patella in a healthy adult. Diagn Interv Imaging 2013;94:108-11.

5. Kakazu T, Tatemoto H, Kawamura M, Sugita T. Sleeve fracture of the upper pole of the patella in an adult with osteogenesis imperfecta. Injury 2003;34:793-4.

6. Houghton GR, Ackroyd CE. Sleeve fractures of the patella in children: A report of three cases. J Bone Joint Surg Br
$1979 ; 61: 165-8$.

7. Xie L, Xu H, Zhang L, Xu R, Guo Y. Sleeve fracture of adult of patella: Case report and review of the literature. Medicine 2017;96:e7096.

8. Gettys FK, Morgan RJ, Fleischli JE. Superior pole sleeve fracture of the patella: Case report and review of the literature. Am J Sports Med 2010;38:2331-6.

9. Bruijn JD, Sanders RJ, Jansen BR. Ossification in the patellar tendon and patella following sports injuries in children. Complications of sleeve fractures after conservative treatment. Arch Orthop Trauma Surg 1993;112:157-8.

10. Sponseller P, Stanitsk C. Fractures in Children. Philadelphia, PA: Lippincott, Williams and Wilkins; 2001. p. 1029.

11. Kaar TK, Murray P, Cashman WF. Transosseous suturing for sleeve fracture of thepatella: Case report. Ir J Med Sci 1993;162:148-9.
Conflict of Interest: Nil

Source of Support: Nil

Consent: The authors confirm that informed consent was obtained from the patient for publication of this case report

\section{How to Cite this Article}

Quraishi F, Khan I, Quraishi AG. Case Report on Sleeve Avulsion of Patella in Young Adult. Journal of Orthopaedic Case Reports 2021 March;11(3): 94-97. 